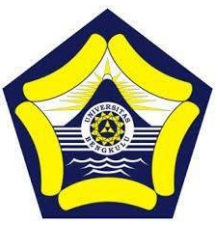

JOLL 4 (2) (2021)

Journal of Lifelong Learning

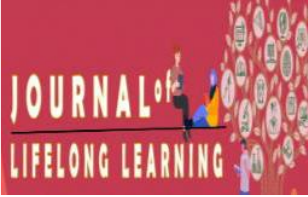

\title{
Pelaksanaan Pembelajaran Life Skill Menjahit Kelompok Belajar Paket C Di PKBM Mutiara Bintang
}

\author{
Rodiah $^{1}$, Sofino², M. Ilham Abdullah ${ }^{3}$ \\ Pendidikan Nonformal Universitas Bengkulu \\ rodiah@gmail.com,sofino@unib.ac.id abdullah418@gmail.com
}

\begin{abstract}
Abstrak
PKBM Mutiara Bintang Kota Bengkulu merupakan salah satu lembaga yang menyelenggarakan pelaksanaan pembelajaran life skill menjahit bagi kelompok belajar paket C pada mata pelajaran muatan lokal dengan bertujuan meningkatkan kemampuan keterampilan menjahit. Penelitian ini bertujuan untuk mengetahui Pelaksanaan pembelajaran life skill menjahit mulai dari perencanaan pembelajaran yang telah dibuat oleh pihak lembaga, proses pembelajaran dari segi kegiatan belajar, faktor penghambat dan faktor pengdukung dalam pelaksanaan pembelajaran, evaluasi pelaksanaan pembelajaran dan keberhasilan hasil belajar dalam pelaksanaan pembelajaran life skill menjahit bagi kelompok belajar. Penelitian dilakukan dengan menggunakan metode kualitatif. Data yang dikumpulkan teknik wawancara, observasi dan dokumentasi. Hasil penelitian pelaksanaan pembelajaran life skill menjahit bagi kelompok belajar paket C yaitu diawali dengan rekrutmen kelompok belajar, persiapan kurikulum,materi,metode dan media dan proses pembelajaran yang dilaksanakan dua kali dalam seminggu dan faktor pengdukung dari segi sarana prasarana dan evaluasi dilakukan dengan dilihat dari hasil belajar paket $C$ dan keberhasilan hasil belajar dilihat dari pembuatan tutup untuk (kulkas,galon dan magicom) dan sarung bantal.
\end{abstract}

Kata Kunci: Pelaksanaan Pembelajaran, Life Skill Menjahit dan PKBM

\section{Abstract}

PKBM Mutiara Bintang Bengkulu City is one of the institutions that organizes the implementation of sewing life skills learning for the package $C$ study group on local content subjects with the aim of improving sewing skills. This study aims to determine the implementation of sewing life skills learning starting from learning plans that have been made by the institution, the learning process in terms of learning activities, inhibiting factors and supporting factors in the implementation of learning, evaluation of learning implementation and the success of learning outcomes in the implementation of sewing life skills learning. for study groups. The research was conducted using qualitative methods. The data collected were interview, observation and documentation techniques. The results of the research on the implementation of sewing life skills learning for the package $C$ study group, which begins with the recruitment of study groups, preparation of the curriculum, materials, methods and media and the learning process which is carried out twice a week and the supporting factors in terms of infrastructure and evaluation is carried out by looking at the results learning package $\mathrm{C}$ and the success of learning outcomes can be seen from the manufacture of lids for (refrigerator, gallon and magicom) and pillowcases.

Keywords: Learning Implementation, Sewing Life Skills and PKBM 


\section{PENDAHULUAN}

Pendidikan merupakan salah satu wadah dalam proses pembelajaran bagi sesorang dalam mengembangkan potensi diri, pengetahuan dan keterampilan. Pendidikan telah diatur dalam UU No.2o Tahun 2003 Pasal 1 tentang Sistem Pendidikan Nasional bahwa :

Pendidikan adalah usaha sadar dan terencana untuk mewujudkan suasana belajar dan proses pembelajaran agar peserta didik secara aktif mengembangkan potensi dirinya untuk memiliki kekuatan spiritual keagamaan, pengendalian diri, kepribadian, kecerdasan, akhlak mulia, serta keterampilan yang diperlukan dirinya, masyarakat, bangsa dan negara.

Oleh karena itu, pendidikan dalam kehidupan masyarakat pada hakekatnya sangat penting, untuk menciptakan pembelajaran bagi kelompok belajar perlu adanya pelaksanaan dan prosedur yang sesuai dengan kebutuhan pembelajaran agar dapat mengembangkan potensi pada kelompok belajar dengan memberikan keterampilan dalam pembelajaran.

Dalam Undang-Undang Nomor 20 Tahun 2003 tentang Sistem Pendidikan Nasional pasal 13 ayat 1 menegaskan bahwa "Jalur pendidikan terdiri dari Pendidikan Formal, Informal dan Nonformal.” Ketiga jalur tersebut satu- kesatuan dalam pendidikan nasional.

Menurut Coombs dan Ahmed dalam Kamil kamil (2011:11) menyatakan bahwa Pendidikan non formal merupakan setiap kegiatan pendidikan yang terorganisir diselenggarakan di luar sistem pendidikan formal,diselenggarakan secara tersendiri atau merupakan bagian penting dari sebuah sistem yang lebih luas dengan maksud memberikan layanan khusus kepada warga belajar atau membantu mengidentifikasi kebutuhan belajar agar sesuai dengan kebutuhan dan mencapai tujuan belajarnya.Menurut Undang-Undang RI No.
20 Tahun 2003 tentang Sistem Pendidikan Nasional Satuan Pendidikan Nonformal terdiri atas Lembaga Kursus, Lembaga Pelatihan, Kelompok Belajar, PKBM dan Majelis Taklim serta satuan pendidikan yang sejenis.

Menurut UNESCO dalam Mustofa Kamil (2011:85) PKBM (Pusat Kegiatan Belajar Masyarakat) adalah salah satu satuan pendidikan nonformal yang diarahkan untuk masyarakat dan juga memberi kesempatan juga pada masyarakat untuk mengelola serta memberikan kesempatan untuk mengembangkan pembelajaran dengan tujuan mengembangkan kemampuan dan pengetahuan pada masyarakat agar mampu bersaing dan memperbaiki kualitas pada dirinya.

Untuk mengembangkan pembelajaran dengan tujuan untuk meningkatkan kemampuan pada kelompok belajar perlu adanya program keterampilan pada pembelajaran pada PKBM.Menurut Gagne dalam Fathurrohman (2012:9) menyatakan bahwa pembelajaran merupakan serangkaian kegiatan yang dirancang untuk memungkinkan terjadinya proses belajar pada siswa.

Salah satu pembelajaran yang diselanggarakan oleh PKBM Mutiara Bintang Kota Bengkulu yakni life skill menjahit yang ada dalam mata pelajaran muatan lokal. Menurut Tita Sukmawati (2008:109) menyatakan bahwa life skill menjahit merupakan kemampuan untuk mengeluarkan kreatifitas dalam upaya mengerjakan proses menyambung kain, bulu, kulit binatang maupun bahan-bahan lain yang bisa dilewati jarum jahit dan benang.

Dengan adanya pelaksanaan pembelajaran life skill menjahit bagi kelompok belajar paket C pada PKBM Mutiara Bintang Kota Bengkulu dapat mengembangkan dan meningkatkan keterampilan life skill menjahit bagi 
kelompok belajar paket Cdan menjadi salah satu upaya positif PKBM Mutiara Bintang dalam pelaksanaan pembelajaran bagi kelompok belajar paket $\mathrm{C}$ sehingga kelompok belajar paket $\mathrm{C}$ yang sudah menyelesaikan pembelajaran life skill menjahit dapat diterapkan dalam lingkungan masyarakat .

\section{METODE}

Metode yang digunakan dalam penelitian ini adalah metode kualitatif. Menurut Sugiyono (2013: 9) menyatakan bahwa metode penelitian kualitatif adalah metode penelitian yang berlandaskan pada filsafat postpositivisme, digunakan untuk meneliti pada kondisi obyek yang alamiah, (sebagai lawannya adalah eksperimen) dimana peneliti adalah sebagai instrumen kunci, teknik pengumpulan data dilakukan secara triangulasi (gabungan), analisis data bersifat induktif/kualitatif, dan hasil penelitian kualitatif lebih menekankan makna dari pada generalisasi.

Adapun informan penelitian atau subjek penelitian ini yaitu:

1. Devi Suryani M,Pd sebagai Ketua PKBM Mutiara Bintang,

2. Desi Lestari sebagai Instruktur Menjahit.

3. Tianty Zea Putri sebagai Kelompok Belajar Paket C.

Penelitian ini dilakukan dalam kurun waktu 4 minggu, dimulai dari tanggal 18 juni sampai 21 juli 2021. Tempat dalam penelitian ini berlokasi di PKBM Mutiara Bintang yang beralamat di jalan putri gading cempaka Rt 15 Rw o1 kelurahan Penurunan Kecamatan Ratu Samban Kota Bengkulu.

Teknik pengumpulan digunakan secara umum yaitu menggunakan:

1. Wawancara

Menurut Sugiyono (2013:137) mengemukakan bahwa wawancara merupakan sebagai teknik pengumpulan data apabila peneliti ingin melakukan studi pendahuluan untuk menemukan permasalahan yang harus diteliti, dan juga apabila peneliti ingin mengetahui hal-hal dari responden yang lebih mendalam dan jumlah responden sedikit/kecil. Dalam penelitian ini akan melakukan wawancara langsung dengan narasumber.

2. Observasi

Menurut Nasution (1988) dalam Sugiyono (2013:226) mengemukan bahwa observasi adalah dasar semua ilmu pengetahuan. para ilmuwan hanya dapat bekerja berdasarkan data, yaitu fakta mengenai dunia kenyataan yang diperoleh melalui observasi.

\section{Dokumentasi}

Menurut Sugiyono (2013:240) mengemukakan bahwa dokumen merupakan:Catatan peristiwa yang sudah berlalu. Dokumen bisa berbentuk tulisan, gambar, atau karya-karya monumental dari seorang.

Sedangkan untuk menguji keabsahan data atau validasi data,peneliti menggunakan trianggulasi:

1. Trianggulasi Subjek

Trianggulasi subjek untuk menguji kredibilitas data dilakukan dengan cara mengecek data yang telah diperoleh melalui beberapa sumber dan membandingkan hasil pengamatan dan data hasil wawancara.

2. Trianggulasi Teknik

Trianggulasi teknik untuk menguji kredibilitas data yang dilakukan dengan cara mengecek data kepada sumber yang sama dengan teknik yang berbeda. Seperti data yang diperoleh dengan wawancara, lalu dicek dengan observasi atau dokumentasi. Bila dengan tiga teknik pengujian kredibilitas data tersebut menghasilkan data yang berbedabeda, maka peneliti melakukan 
diskusi lebih lanjut kepada sumber data yang bersangkutan yang lain.

Adapun teknik analisis data yang digunakan dalam penelitian ini adalah teknik analisis data Analisis data dalam penelitian kualitatif dilakukan sejak sebelum memasuki lapangan, selama di lapangan, dan setelah selesai di lapangan.

Menurut Miles dan Huberman (1992) dalam (Afrizal 2015: 178), tahapan teknik analisis data ada 3 macam yaitu, reduksi data, penyajian data, dan penarikan kesimpulan atau verifikasi.

1. Reduksi Data

Reduksi data merupakan pengumpulan data penelitian, seorang peneliti dapat menemukan kapan saja waktu untuk mendapatkan data yang banyak, apabila peneliti mampu menerapkan metode observasi, wawancara atau dari berbagai dokumen yang berhubungan dengan subjek yang diteliti.

2. Penyajian Data (data display)

Setelah data reduksi, maka langkah selanjutnya adalah mendisplaykan data. Penyajian data dalam bentuk uraian singkat dan tabel. Pendisplayan data digunakan untuk menyajikan data dalam penelitian ini adalah dengan teks yang bersifat naratif atau berupa deskripsi, serta tabel untuk mempermudah memahami hasil penelitian.

3. Mengambil Kesimpulan atau Verifikasi

Mengambil kesimpulan merupakan analisis lanjutan dari reduksi data dan display data sehingga data dapat disimpulkan, dan peneliti masih berpeluang untuk menerima masukan..Data tentang Peneliti mencari makna dari setiap gejala yang diperoleh dilapangan, mencatat keteraturan atau pola penjelasan dan konfigurasi yang mungkin ada, alur kausalitas, dan proposisi. Selama penelitian masih berlangsung, setiap kesimpulan yang ditetapkan terus menerus diverifikasi hingga benarbenar diperoleh konklusi yang valid dan kokoh.

\section{HASIL DAN PEMBAHASAN}

PKBM Mutiara Bintang Kota Bengkulu berdiri PKBM Mutiara Bintang berdiri pada tanggal 16 januari 2011 yang dicetuskan oleh ibu Devi Suryani M,Pd.I yang dilandasi oleh banyaknya masyarakat disekitar yang tidak menamatkan pendidikan formal di sekolah dimana kebanyakan dari kalangan anak-anak yang masih di bawah umur.Saat itu, ibu Devi Suryani M,Pd.I berinisiatif mendirikan PKBM di bawah yayasan Cahaya Mutiara Rabbani di Kota Bengkulu yang berlamatkan di jalan putri gading cempaka Rt $15 \quad \mathrm{Rw}$ o1 kelurahan Penurunan Kecamatan Ratu Samban Kota Bengkulu.PKBM Mutiara Bintang mempunyai program-program pendidikan seperti Pendidikan kesetaraan paket A, B, dan C,Pendidikan anak usia dini (Paud) ,kursus computer,kursus seni dan kursus menjahit

Berdasarkan penemuan peneliti melalui wawancara dengan 3 informan penelitian dan melakukan observasi langsung ke lapangan untuk mengetahui tentang pelaksanaan pembelajaran life skill menjahit bagi kelompok belajar paket C pada PKBM Mutiara Bintang Kota Bengkulu.

Dalam pelaksanaan pembelajaran life skill menjahit bagi kelompok belajar paket $C$, perlu adanya perencanaan pembelajaran terlebih dahulu. Menurut Menurut Sudjana dalam(Tita sukmawati 2018:108) menyatakan bahwa perencanaan dalam pembelajaran yaitu meliputi identifikasi kebutuhan, tujuan pembelajaran, kurikulum, sumber belajar (materi), sumber dana dan strategi (metode) pembelajaran Sehingga dapat diketahui bahwa perencanaan pembelajaran dapat bekerjasama antara instruktur dan 
kelompok belajar untuk mencapai tujuan pembelajaran yang telah ditentukan sebelumnya. Di lembaga PKBM Mutiara Bintang perencanaan pembelajaran life skill menjahit yaitu merekrut atau mendaftarkan kelompok belajar khususnya paket $C$ untuk mengikuti life skill (menjahit, komputer dan seni) yang telah dipersiapkan oleh pihak lembaga dengan bertujuan untuk menambah keterampilan atau kemampuan dalam diri kelompok belajar dan mempermudah dalam mencari pekerjaan atau memulai usaha sendiri sesuai kemampuan yang dimiliki dan perlu kurikulum, materi dan metode media dalam perencanaan pelaksanaan pembelajaran life skill menjahit.

Dalam pelaksanaan pembelajaran life skill menjahit bagi kelompok belajar perlu diketahui proses pembelajaran. Menurut Muhammad Andi Setiawan (2017:126) menyatakan bahwa Proses pembelajaran merupakan interaksi antara guru atau pengajar dengan peserta didik untuk melakukan kegiatan belajar dan mengajar dengan menggunakan berbagai sarana dan prasarana untuk mencapai tujuan pembelajaran yang sudah ditentukan.

Berdasarkan pendapat dari Muhammad Andi Setiawan (2017:126), peneliti dapat menyimpulkan bahwa proses pembelajaran kegiatan yang dilakukan instruktur dan kelompok belajar untuk berinteraksi dalam pembelajaran life skill menjahit dengan sarana prasarana yang telah disiapkan oleh pihak lembaga PKBM Mutiara Bintang. Dalam pembelajaran life skill menjahit terdapat interaksi antara instuktur menjahit dan kelompok belajar dalam kegiatan belajar life skill menjahit yang dilaksanakan dua kali dalam seminggu dan dilaksanankan selama empat jam. Menurut Muhammad Andi Setiawan (2017:126) Guru dan peserta didik. Guru dan peserta didik merupakan bagian yang sangat penting dari proses pembelajaran. Tanpa adanya guru dan peserta didik maka proses pembelajaran tidak dapat terlaksana.terakhir sarana prasarana yang digunakan dalam pembelajaran life skill menjahit ialah ruangan belajar menjahit dan mesin jahit, mesin jahit jahit yang digunakan yakni mesin jahit manual, mesin jahit portable dan mesin jahit obras dan juga alat-alat dalam menjahit ialah meteran,gunting, jarum jahit, benang, kain,jarum pentul dan sebagainya. Menurut Muhammad Andi Setiawan (2017:126) Sarana prasarana membantu mempermudah dan memfasilitasi terlaksananya proses pembelajaran yang menarik, efektif dan mudah dipahami. Sarana prasarana mencakup tempat pembelajaran, ruangan, alat atau media pembelajaran lainnya dll.

Dalam pelaksanaan pembelajaran life skill menjahit bagi kelompok belajar paket C mempunyai faktor penghambat dan pendukung dalam pembelajaran life skill menjahit. Menurut Nindri R. Sucipto (142:2015) faktor penghambat merupakan terbatasnya waktu belajar yang sangat singkat sehingga alokasi waktu tidak sesuai dengan beban materi yang diterima warga belajar. Dapat disimpulkan dari teori di atas bahwa Faktor penghambat dalam pelaksanaan pembelajaran life skill menjahit yakni susah dalam mengatur waktu dalam pembelajaran life skill menjahit karena pembelajaran pada kelompok belajar paket C tidak sama dengan pendidikan formal, maka perlunya ada kesepakatan dari instruktur dan kelompok belajar dalam menentukan waktu pembelajaran life skill menjahit.

Selanjutnya faktor pendukung, Menurut Nindri R. Sucipto (2015:142) faktor pengdukung merupakan adanya hubungan mitra kerja dengan lembaga sehingga proses pembelajaran lebih berkualitas, Instruktur yang berkompeten yaitu memiliki kualitas dalam bidang menjahit dan mampu mengelola pembelajaran, materi yang dirancang sesuai dengan dunia usaha dan dunia industry seperti keselamatan dalam bekerja dengan menyiapkan tempat dan alat kerja, memelihara dan menyiapkan alat jahit, menjahit bagian -bagian potongan pakaian menyetrika bagian pakaian dan merapikan tempat kerja dan alat kerja. Dapat disimpulkan teori diatas bahwa faktor pengdukung dalam pelaksanaan pembelajaran life skill menjahit yakni dari segi sarana dan prasarana seperti ruangan 
belajar menjahit dan mesin jahit yang dipakai dalam pembelajaran life skill menjahit yakni mesin jahit manual, mesin jahit portable dan mesin jahit obras dan Instruktur menjahit yang berkompeten.

Dalam evaluasi pelaksanaan pembelajaran life skill menjahit pada mata pelajaran muatan lokal bagi kelompok belajar paket $C$ terdapat aspek- aspek yang dinilai oleh lembaga PKBM Mutiara Bintang dalam pelaksanaan pembelajaran life skill menjahit dan yang terlibat dalam evaluasi pembelajaran life skill menjahit. Menurut Muhammad Andi Setiawan (2017:160) evaluasi pembelajaran adalah proses penilaian atau pengukuran secara sistematis terhadap tujuan pembelajaran yang telah ditetapkan.dapat disimpulkan bahwa evaluasi pembelajaran ialah suatu proses penilaian dari hasil pembelajaran yang dilaksanaan oleh lembaga pendidikan untuk mengetahui hasil dari kegiatan yang telah dilaksanaan. Orang- orang yang terlibat dalam proses penilaian dari hasil pembelajaran life skil menjahit ialah ketua PKBM Mutiara Bintang dan Instruktur menjahit dan proses penilaian atau evaluasi yakni untuk mengetahui hasil belajar menjahit kelompok belajar paket $\mathrm{C}$ dilihat dari penilaian hasil teori, penilaian hasil praktek, absensi (kehadiran) dan sikap.

Dalam pelaksanaan pembelajaran life skill menjahit pada bagi kelompok belajar terdapat wujud kerberhasilan dari pembelajaran life skill menjahit. Menurut Mahmudah (2018:68) Keberhasilan merupakan sebuah ukuran dalam proses pembelajaran. Dapat disimpulkan dari teori diatas bahwa keberhasilan ialah bentuk keberhasilan dari pelaksanaan pembelajaran yang dipelajari oleh kelompok belajar. Wujud keberhasilan dalam pelaksanaan pembelajaran life skill menjahit pada mata pelajaran muatan lokal ialah hasil membuat seprai,sarung bantal, tutup (untuk kulkas,galon,magicom) dan hasil jahitan yang dilihat kerapian dan pola yang bagus dalam menjahit, untuk sertifikat life skill menjahit belum ada untuk kelompok belajar karena pembelajaran masih di level satu (permulaan).

\section{KESIMPULAN}

$\begin{array}{ccc}\text { Dari } & \text { penelitian yang telah } \\ \text { dilaksanakan } & \text { dapat disimpulkan }\end{array}$ pelaksanaan pembelajaran life skill menjahit bagi kelompok belajar paket $\mathrm{C}$, terdapat adanya perencanaan pembelajaran. Di lembaga PKBM Mutiara Bintang perencanaan pembelajaran life skill menjahit yaitu merekrut atau mendaftarkan kelompok belajar khususnya paket $C$ untuk mengikuti life skill (menjahit, komputer dan seni) yang telah dipersiapkan oleh pihak lembaga dengan bertujuan untuk menambah keterampilan atau kemampuan dalam diri kelompok belajar dan mempermudah dalam mencari pekerjaan atau memulai usaha sendiri sesuai kemampuan yang dimiliki dan perlu kurikulum, materi dan metode media dalam perencanaan pelaksanaan pembelajaran life skill menjahit. selanjutnya terdapat factor pendukung dalam kegiatan pelaksaaan pelatihan life skill menjahit sarana dan prasarana seperti ruangan belajar menjahit dan mesin jahit yang dipakai dalam pembelajaran life skill menjahit yakni mesin jahit manual, mesin jahit portable dan mesin jahit obras dan Instruktur menjahit yang berkompeten. dan temuan terakhir yakni danya evaluasi dari pelaksanaan pembelajaran life skill menjahit evaluasi pembelajaran ialah suatu proses penilaian dari hasil pembelajaran yang dilaksanaan oleh lembaga pendidikan untuk mengetahui hasil dari kegiatan yang telah dilaksanaan. Orang- orang yang terlibat dalam proses penilaian dari hasil pembelajaran life skill menjahit ialah ketua PKBM Mutiara Bintang dan Instruktur menjahit dan proses penilaian atau evaluasi yakni untuk mengetahui hasil belajar menjahit kelompok belajar paket $C$ dilihat dari penilaian hasil teori, penilaian hasil praktek, absensi (kehadiran) dan sikap.

\section{DAFTAR PUSTAKA}

Afrizal.2014. Metode penelitian kualitatif. Depok. Rajagrafindo Persada

Agustrian, N.L, Rizkan \& Izzudin,M. 2018. Manajemen Program Life Skill Di Rumah Singgah Al-Hafidz Kota 
Bengkulu. Journal of Community

Development, 1 (1)

Depdiknas (2003). Undang-undang RI

No.20 tahun 2003 Tentang System

Pendidikan Nasional. Depdiknas. Jakarta.

Fhaturrrohman. 2012.Belajar dan

Pembelajaran.Yogyakarta:Penerbit

Teras

Kisworo,Bagus.2017. Implementasi Media Pembelajaran Berbasis Prinsip-Prinsip Pendidikan Orang Dewasa di Pkbm Indonesia Pusaka Ngaliyan Semarang. Journal of Nonformal Education, 3 (1) 8o-86

Latifa, T., \& Maeliah, M. (2014). Manfaat hasil belajar keterampilan menjahit tailor sebagai kesiapan magang di tailor. Fesyen Perspektif, 6(1).

Lestari, S., Winarni, E.W, Wurjinem. Pengaruh Bahan Ajar Muatan Lokal Konservasi Flora Khas Bengkulu Terhadap Sikap Peduli Lingkungan Siswa Kelas V Sekolah Dasar Di Kota Bengkulu. Jurnal Riset Pendidikan Dasar, 1(1) : 29 -35

Mahmudah, M. (2018). Pengelolaan Kelas: Upaya Mengukur Keberhasilan Proses Pembelajaran. Jurnal Kependidikan, 6(1), 53-70.

Mustafa, Kamil. (2009). Model Pendidikan dan Pelatihan Konsep dan Aplikasi. Bandung: Alfabeta

Noor,Agus Hasbi.2015.Pendidikan kecakapan hidup (Life Skill) Di Pondok pesantren Dalam Meningkatkan Kemandandirian Santri.Jurnal Empowerment.3 (1)

Pane, Aprida, and Muhammad Darwis Dasopang. "Belajar dan pembelajaran." Fitrah: Jurnal Kajian Ilmu-Ilmu Keislaman 3.2 (2017): 333-352.

Setiawan,Andi.2017. Belajar Dan Pembelajaran. Ponorogo: Uwais Inspirasi Indonesia

Sucipto, Nindri Rakhmadani dan Joko Sutarto.2015.Pemberdayaan

Masyarakat Miskin Untuk Meningkatkan Kecakapan Hidup Melalui Kursus Menjahit di LKP Elisa Tegal.Journal of nonformal education and community empowermen, $\mathbf{t} 4.2$
Sugiyono.2013.Metode penelitian kuantitatif kualitatif dan RED.Bandung:Alfabeta.

Sukmawati,Tita.2018.Upaya LKP Lucky Dalam Meningkatkan Keterampilan Melalui Kursus Menjahit (studi kualitatif bagi kalangan perempuan di LKP Lucky Desa Tanimulya Kec. Ngamprah Kab. Bandung Barat).Jurnal Comm-Edu.1 (2):108

Tim pengembangan MKDP kurikulum dan pembelajaran (2012). Kurikulum dan Pembelajaran. Jakarta: PT. Raja Grafindo Persada

Yani, Ivo. 2019. Efektivitas Pembelajaran Komputer Bersertifikat Lembaga Kursus Dan Pelatihan Pada Mata Pelajaran Muatan Lokal Paket C. Jurnal Ilmiah VISI PGTK PAUD dan Dikmas.vol.14 (2) 